\begin{tabular}{|c|c|c|}
\hline 89 & $\begin{array}{c}\text { European Association for the } \\
\text { Development of Renewable Energies, Environment } \\
\text { and Power Quality (EA4EPQ) }\end{array}$ & $\begin{array}{l}\text { International Conference on Renewable Energies and Power Quality } \\
\text { (ICREPQ'12) } \\
\text { Santiago de Compostela (Spain), 28th to 30th March, } 2012\end{array}$ \\
\hline
\end{tabular}

\title{
Advanced Superconducting Power Conditioning System for Effective Use of Renewable Energy
}

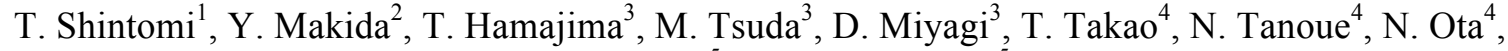 \\ K. Munakata ${ }^{5}$, and M. Kajiwara ${ }^{5}$ \\ ${ }^{1}$ Advanced Research Institute for the Science and Humanities, Nihon University \\ 12-5, 5-Bancho, Chiyoda-ku, Tokyo 102-8251, Japan \\ Phone: +81-5275-7942, Fax: +81-5275-9204, e-mail: shintomi.takakazu@nihon-u.ac.jp \\ ${ }^{2}$ Institute of Particle and Nuclear Studies, High Energy Accelerator Research Organization \\ 1-1 Oho, Tsukuba, Ibaraki 305-0801, Japan \\ ${ }^{3}$ Electrical Communication Engineering Department, Graduate School, Tohoku University \\ 05 Aoba, Aramaki, Aoba-ku, Sendai 980-8579, Japan \\ ${ }^{4}$ Department of Engineering and Applied Sciences, Sophia University \\ 7-1 Kioi-cho, Chiyoda-ku, Tokyo 102-8554 Japan \\ ${ }^{5}$ Iwatani Corporation \\ 3-6-4 Hom-machi, Chuo-ku, Osaka 541-0053, Japan
}

\begin{abstract}
In order to use effectively renewable energy sources, we propose a new system, called Advanced Superconducting Power Conditioning System (ASPCS) that is composed of Superconducting Magnetic Energy Storage (SMES), Fuel Cell-Electrolyzer (FC-EL), hydrogen storage and dc/dc and $\mathrm{dc} / \mathrm{ac}$ converters in connection with a liquid hydrogen station for fuel cell vehicles. The ASPCS compensates the fluctuating electric power of renewable energy sources such as wind and photovoltaic power generations by means of the SMES having characteristics of quick response and large I/O power, and hydrogen energy with FC-EL having characteristics of moderate response and large storage capacity.
\end{abstract}

The moderate fluctuated power generations of the renewable energy are compensated by a trend prediction with the Kalman filtering algorithm. In case of excess of the power generation by the renewable energy to demand it is converted to hydrogen with EL. On the contrary, in case of shortage the electric power is made up with FC. The faster fluctuation that cannot be compensated by the prediction method is effectively compensated by SMES. In the ASPCS, the SMES coil with an $\mathrm{MgB}_{2}$ conductor is operated at $20 \mathrm{~K}$ by using liquid hydrogen supplied from a liquid hydrogen tank of the fuel cell vehicle station. The necessary storage capacity of SMES is estimated as $50 \mathrm{MJ}$ to $100 \mathrm{MJ}$ depending on the prediction time for compensating fluctuation of the rated wind power generation of 5 MW. As a safety, a thermo-siphon cooling system is used to cool indirectly the $\mathrm{MgB}_{2}$ SMES coil by thermal conduction.

The concept of the ASPCS and the design study of the SMES are reported.

\section{Key words}

Liquid hydrogen, SMES, renewable energy, fuel cell and electrolyzer, $\mathrm{MgB}_{2}$ superconductor.

\section{Introduction}

It is an urgent issue to reduce carbon-dioxide, and hence renewable energy, that is environmentally friendly, should be supplied as sources of a large amount of the electric energy. The wind and photovoltaic power generations are expected as promising renewable energy sources because they are clean without carbon dioxide and out of anxiety of exhaustion. From the energy security point of view, the renewable energy sources become more and more important.

Recently the introduction of those energy sources becomes quite rapid and surprisingly increasing. However, they have a demerit of unstable power source depending on the weather. The installation of a large amount of such sources makes electric power networks unstable, and then it is required to install some kinds of measures for buffering the fluctuation.

Hydrogen as secondary energy is also clean and renewable energy in utilization of the fuel cell (FC) and 
the electrolyzer (EL). Hydrogen has a large storage capacity and it is effective to use it as a buffer of the fluctuation of the renewable energy. Moreover, it is expected for hydrogen stations for FC vehicles to become popular in the near future [1].

In order to compensate the fluctuation of the renewable energy sources and use them effectively, we propose a new system called an Advanced Superconducting Power Conditioning System (ASPCS) that is composed of superconducting magnetic energy storage (SMES), FC-EL, hydrogen storage, and $\mathrm{dc} / \mathrm{dc}$ and $\mathrm{dc} / \mathrm{ac}$ converters. The ASPCS is combined with liquid hydrogen stations for FC vehicles.

Recently superconducting devices using $\mathrm{MgB}_{2}$ conductors have been developed [2]-[4] and possibility of $\mathrm{MgB}_{2}$ magnets by cooling liquid hydrogen was proposed [5], [6]. Moreover, the studies on such magnets for power applications have been carried out [7]-[12].

The concept of the ASPCS and the design study of the SMES with $\mathrm{MgB}_{2}$ conductors that is one of the important componets of the ASPCS system are reported.

\section{Concept of Advanced Superconducting Power Conditioning System (ASPCS)}

The ASPCS is composed of SMES with $\mathrm{MgB}_{2}$ conductor cooled at $20 \mathrm{~K}$ using cryogen of liquid hydrogen, FC-EL, $\mathrm{dc} / \mathrm{dc}$ and $\mathrm{dc} / \mathrm{ac}$ converters, and a liquid hydrogen storage of a vehicle station as shown in Fig. 1. The ASPCS is connected to wind and photovoltaic power generators to compensate their fluctuations. The proposed system is assumed to use dc bus lines, and each component is connected to each other through $\mathrm{dc} / \mathrm{dc}$ and $\mathrm{dc} / \mathrm{ac}$ converters. In this study, it is fixed that the wind power generation is 5 MW and the output power of SMES is $1 \mathrm{MW}$.

The wind power generation, for example, contains a moderate-term fluctuations of a few tens minutes and over and a short-term ones of several minutes and below. The moderate-term fluctuations can be compensated with FCEL by a trend prediction using the Kalman filtering

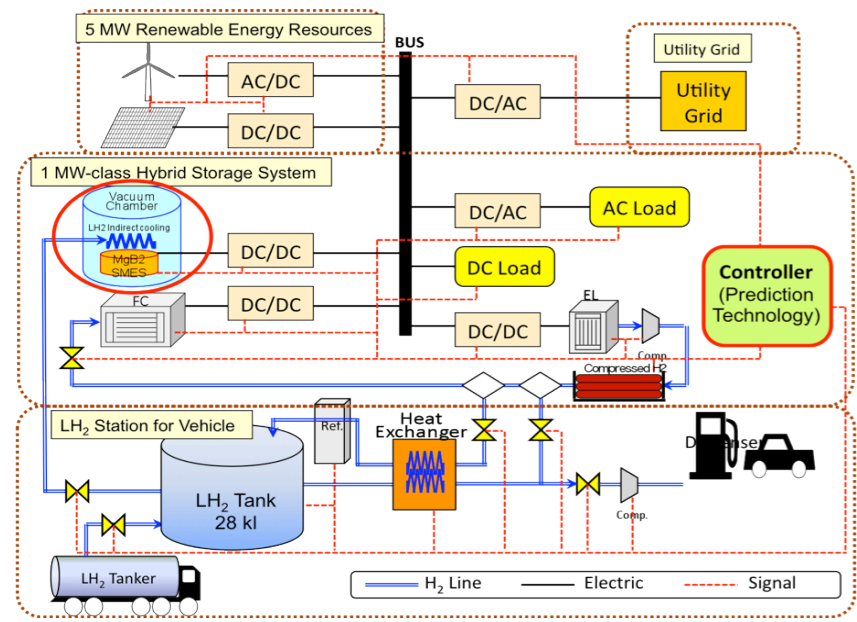

Fig. 1. The concept of the Advanced Superconducting Power Conditioning System (ASPCS).

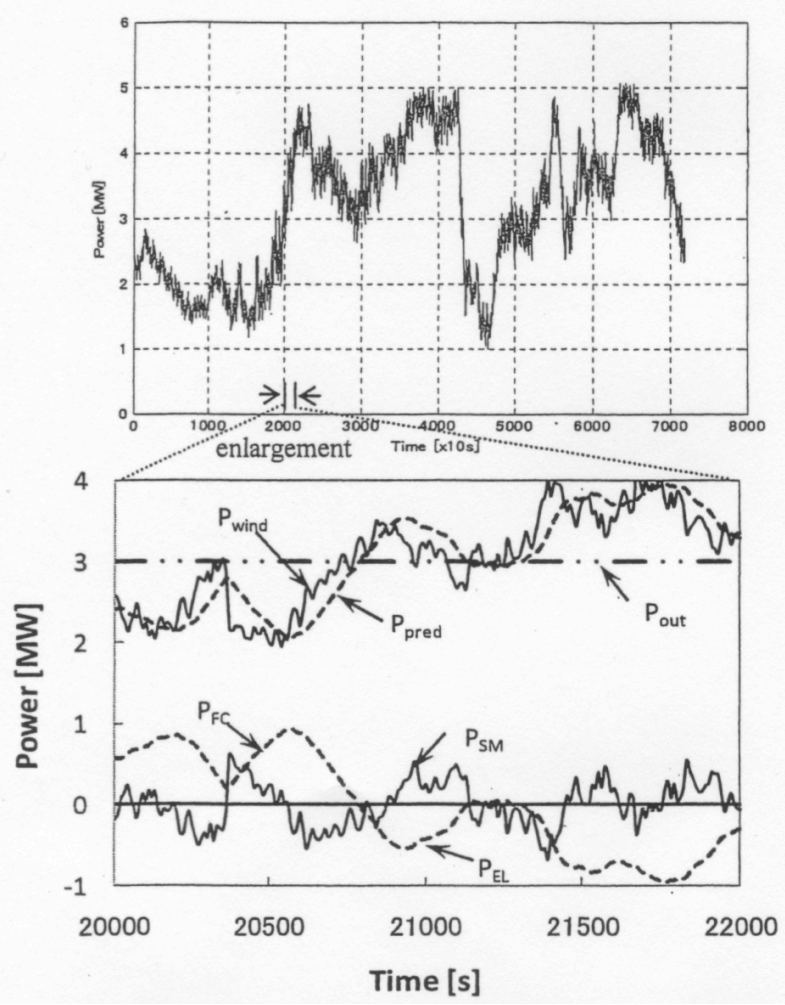

Fig. 2. The typical waveforms of thewind turbine power generation (1 MW $\mathrm{x} 5$ sets) and the compensation of the fluctuation. $\mathrm{P}_{\text {wind }}$ : actual wind power, $\mathrm{P}_{\text {pred }}$ : predicted wind power, $\mathrm{P}_{\text {out }}$ : power demand, $\mathrm{P}_{\mathrm{SM}}$ : SMES compensation power, $\mathrm{P}_{\mathrm{EL}}$ : converted power to hydrogen with $\mathrm{EL}$, and $\mathrm{P}_{\mathrm{FC}}$ : generated power with FC.

algorithm [11]. The compensated moderate-term power generation over the electric power demand is converted to hydrogen with EL and stored into a high pressure gas vessel or the liquid hydrogen reservoir of the vehicle station. On the contrary, the required electric power is generated with FC in case of shortage to the power demand. Figure 2 shows the compensation of the wind power generation. The wind power generation $\mathrm{P}_{\text {wind }}$ is predicted as $\mathrm{P}_{\text {pred }}$ by the Kalman filtering algorism. In case that the $\mathrm{P}_{\text {pred }}$ is less than the power demand $\mathrm{P}_{\text {out }}$, the necessary electric power $\mathrm{P}_{\mathrm{FC}}$ is generated with $\mathrm{FC}$. On the contrary, the surplus power $\mathrm{P}_{\mathrm{EL}}$ is converted to hydrogen with EL in case that $\mathrm{P}_{\text {pred }}$ is over $\mathrm{P}_{\text {out }}$. Then the moderate-term fluctuations can be compensated as shown in the figure.

On the other hand, the short-term fluctuations, that cannot be predicted, are to be compensated with the SMES unit that has characteristics of fast response and large $\mathrm{I} / \mathrm{O}$ power. $\mathrm{P}_{\mathrm{SM}}$ is input and output power of the SMES unit to compensate the fast fluctuations.

\section{Optimization of SMES Capacity}

The input and output energy of SMES is given by

$$
E_{S M E S}=\int\left|P_{\text {wind }}-P_{\text {pred }}\right| d t
$$

The necessary storage capacity of SMES for the compensation depends on the prediction time and the necessary capacity becomes smaller for the shorter 


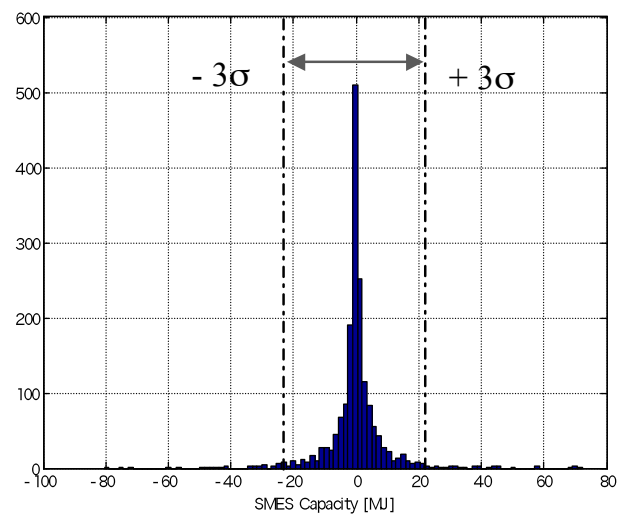

Fig. 3. Histogram of SMES input and output energies in case of the prediction time of 10 seconds. In order to cover the compensation with $\pm 3 \sigma(99.7 \%)$, the necessary I/O energy capacity of SMES is 45 MJ.

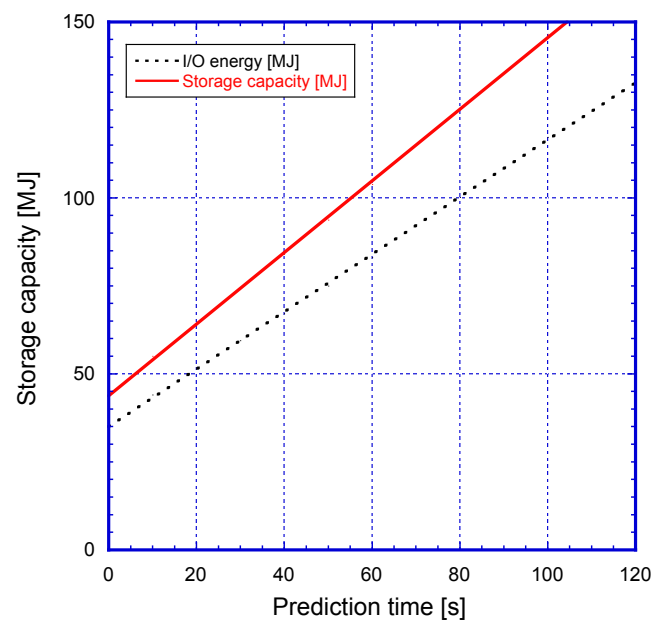

Fig. 4. Necessary storage capacity and I/O energy of SMES vs. the prediction time. In case of the prediction time of 10 seconds, the necessary SMES storage capacity is $55 \mathrm{MJ}$.

prediction time. The prediction time is related to the startup time of FC. We assume to use PEFC which has the start-up time of 10 seconds from the standby and 60 seconds from the cold start.

We estimated the distribution of the I/O energy of SMES given in Eq. 1 for the typical wind power waveform in case of the prediction time of 10 seconds as shown in Fig. 3. The histogram shows almost the normal distribution. When it is assumed that SMES covers the I/O energy of \pm $3 \sigma$ in the distribution, the SMES I/O capacity is $45 \mathrm{MJ}$. Since $80 \%$ of the maximum stored energy is usually available, 50 MJ-class SMES is required. As the same manner, 100 MJ-class SMES is necessary in case of the prediction time of 60 seconds. The relation of the SMES I/O energy and the necessary SMES storage capacity versus the prediction time is shown in Fig. 4.

\section{Design of SMES}

\section{A. Properties of $\mathrm{MgB}_{2}$ Conductor}

The SMES coil is made by an $\mathrm{MgB}_{2}$ conductor, whose $T_{\mathrm{c}}$ is $39 \mathrm{~K}$, cooled at $20 \mathrm{~K}$ using liquid hydrogen. In

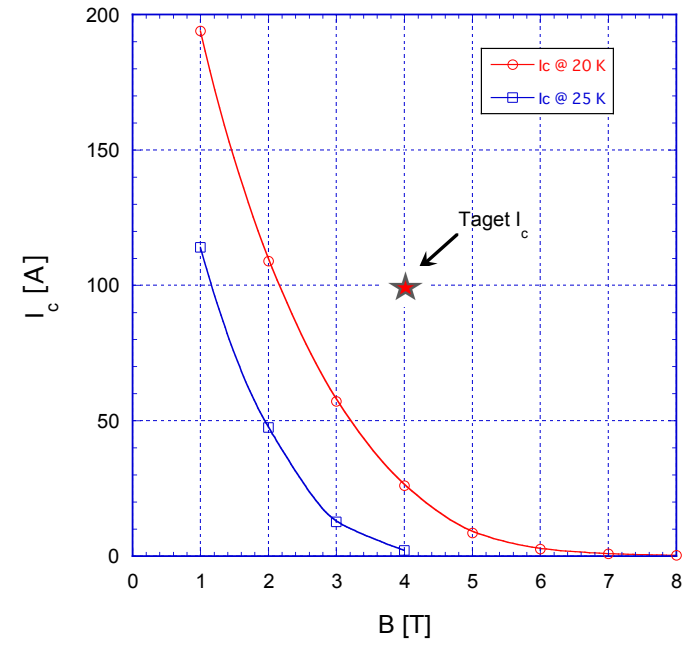

Fig. 5. The $I_{\mathrm{c}}-B$ properties of the existing $\mathrm{MgB}_{2}$ wire. The properties of the $\mathrm{MgB}_{2}$ conductor is expected to improve in the near future at the target value.

consideration of the $I_{\mathrm{c}}-B$ characteristics of the $\mathrm{MgB}_{2}$ conductors at $20 \mathrm{~K}$, the maximum acceptable magnetic field is limited to $2.5 \mathrm{~T}$ at this moment. However, it is expected that the $I_{\mathrm{c}}-B$ properties will be improved in the near future. Figure 5 shows the $I_{\mathrm{c}}-B$ properties of the existing $\mathrm{MgB}_{2}$ wire developed by Hyper Tech Research Inc. at $20 \mathrm{~K}$ and $25 \mathrm{~K}$ [13]. Though $I_{\mathrm{c}}$ is $100 \mathrm{~A}$ at $2 \mathrm{~T}$ and $20 \mathrm{~K}$ at present, the target $I_{\mathrm{c}}$ is expected to be $100 \mathrm{~A}$ at 5 $\mathrm{T}$ and $20 \mathrm{~K}$. Using these $I_{\mathrm{c}}-B$ properties, we designed two types of SMES coils, that is to say, a solenoid type and a toroid type.

\section{B. Solenoid Coil}

We designed the 50 MJ SMES solenoid coil that is composed of four poles with a basic coil of $10 \mathrm{MJ}$. This configuration has merits of fabricating a smaller scale unit and reduction of the leakage magnetic field. The design has been performed for $2 \mathrm{~T}$ solenoid and $5 \mathrm{~T}$ solenoid. The former is conservative using the existing wire and the latter is expecting.

In case of the $2 \mathrm{~T}$ solenoid, the coil size becomes much larger and then it has to take into consideration the transportation of the completed coil from a factory to a site. The SMES is consisted of four basic coils each of which has the inner diameter, the outer diameter and the height of $1.45 \mathrm{~m}, 1.75 \mathrm{~m}$ and $3.1 \mathrm{~m}$, respectively. The calculated ampere-turns of the basic coil is 5.6 MAT. The maximum coil voltage is selected as $1 \mathrm{kV}$ for safety and the available SMES energy is assumed to be $80 \%$ of the maximum stored energy. Since the SMES system has to be operated at the output power of $1 \mathrm{MW}$ in the whole range from the minimum stored energy of $8.8 \mathrm{MJ}$ to 44 MJ, the maximum coil current becomes $2.2 \mathrm{kA}$.

The basic coil is made by the double pancake winding and pure aluminum plates are inserted between the double pancakes for conduction cooling with a thermosiphon cooling system as described in the following 


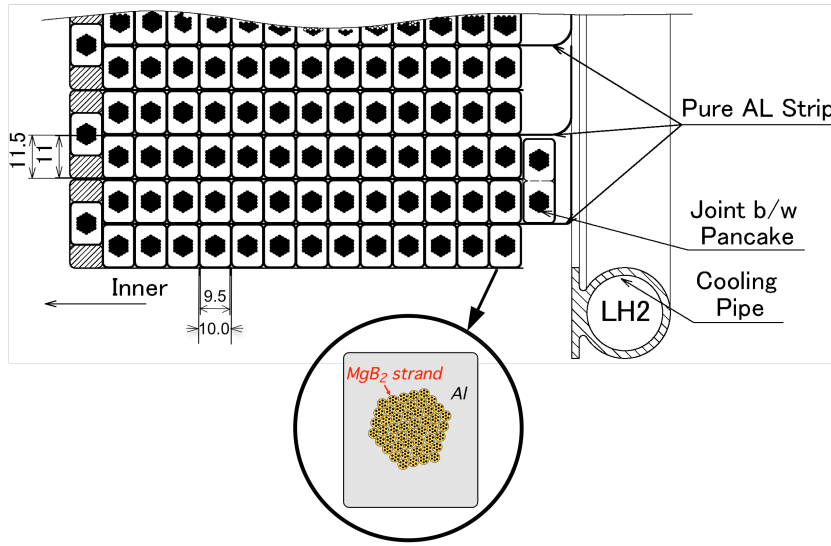

Fig. 6 . The coil configuration of the $10 \mathrm{MJ}$ basic coil. The coil is cooled by conduction with the liquid hydrogen cooling pipe which is a component of the thermo-siphon cooling system.

chapter. The cable for the coil is made by co-extruding stranded $\mathrm{MgB}_{2}$ wires with pure aluminum. The coil configuration is shown in Fig. 6.

In case of the $5 \mathrm{~T}$ solenoid, the coil size becomes much compact. The coil is designed to have a minimum quantity of the $\mathrm{MgB}_{2}$ conductor. The coil diameter is almost same as that of the $2 \mathrm{~T}$ coil. However, the coil height is onesixth of that of the $2 \mathrm{~T}$ coil. The amount of the conductor for the $5 \mathrm{~T}$ coil is also two-third of that of the $2 \mathrm{~T}$ coil.

The design parameters are shown in Table I.

Table I. - Parameters of SMES solenoids for $2 \mathrm{~T}$ and $5 \mathrm{~T}$

\begin{tabular}{|c|l|c|c|}
\hline \multicolumn{2}{|c|}{ Type } & $2 \mathrm{~T}$ & $5 \mathrm{~T}$ \\
\hline Power & Constant output power & \multicolumn{2}{|c|}{$1 \mathrm{MW}$} \\
\hline & Max. operating current & \multicolumn{2}{|c|}{$2.2 \mathrm{kA}$} \\
\hline & Max. operating voltage & \multicolumn{2}{|c|}{$1 \mathrm{kV}$} \\
\hline $\begin{array}{c}\text { Basic } \\
\text { coil }\end{array}$ & Stored energy & $10 \mathrm{MJ}$ & $11 \mathrm{MJ}$ \\
\hline & Magnetic motive force & $5.6 \times 10^{6} \mathrm{~A}$ & $3.3 \times 10^{6} \mathrm{~A}$ \\
\hline & Coil inner diameter & $1.45 \mathrm{~m}$ & $1.6 \mathrm{~m}$ \\
\hline & Coil outer diameter & $1.75 \mathrm{~m}$ & $2.0 \mathrm{~m}$ \\
\hline & Coil height & $3.1 \mathrm{~m}$ & $0.485 \mathrm{~m}$ \\
\hline & Operating temperature & \multicolumn{2}{|c|}{$20 \mathrm{~K}$} \\
\hline $\begin{array}{c}\text { 4-pole } \\
\text { coil }\end{array}$ & Stored energy & $44 \mathrm{MJ}$ & $50 \mathrm{MJ}$ \\
\hline & Max. flux density & $2.39 \mathrm{~T}$ & $5.01 \mathrm{~T}$ \\
\hline & Hoop force & $25.4 \mathrm{MN}$ & $28.7 \mathrm{MN}$ \\
\hline & Compression force & $3.7 \mathrm{MN}$ & $12.4 \mathrm{MN}$ \\
\hline & Centripetal force & $1.26 \mathrm{MN}$ & $2.54 \mathrm{MN}$ \\
\hline Cable & Material & \multicolumn{2}{|c|}{$\mathrm{MgB}_{2}$} \\
\hline & Amount of conductor & $113 \times 10^{6} \mathrm{Am}$ & $75 \times 10^{6} \mathrm{Am}$ \\
\hline
\end{tabular}

\section{Toroid Coil}

The SMES coil of $100 \mathrm{MJ}$ is designed by the toroid type. The magnetic forces, the temperature stability of the coil and the coil protection are taken into consideration. The cable-in-conduit conductor is used as shown in Fig. 7. In consideration of the future development of the $\mathrm{MgB}_{2}$ conductors, the size of the $5 \mathrm{~T}$ coil becomes almost half of that of the $2 \mathrm{~T}$ coil as shown in Fig. 8. It is estimated that the necessary amount of the superconductor of the $5 \mathrm{~T}$ coil becomes $74 \%$ of that of the $2 \mathrm{~T}$ coil. In addition, the

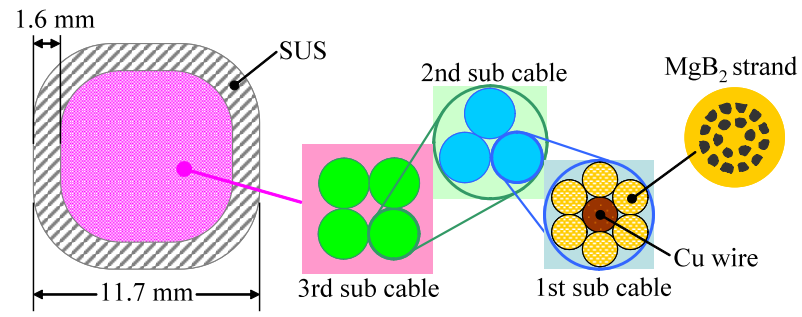

Fig.7. The conductor for the $100-\mathrm{MJ}$ toroid SMES coil. Total of $96 \mathrm{MgB}_{2}$ wires consists of the cable-in-couduit conductor.
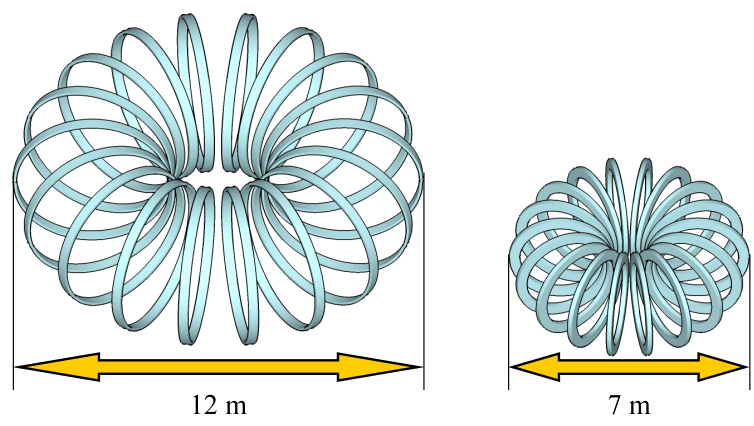

Fig. 8. Comparison of the size of the $2 \mathrm{~T}$ and $5 \mathrm{~T}$ SMES toroid coils.

leakage of the magnetic field becomes smaller in comparison to the $2 \mathrm{~T}$ toroid. The magnetic forces of the $5 \mathrm{~T}$ toroid coil are acceptable. The unit coil of the toroid is also made by the double pancake winding, and cooled indirectly with the thermo-siphon system as same as the solenoid type.

The design parameters of the SMES toroids are shown in Table II.

Table II. - Parameters of SMES toroids for $2 \mathrm{~T}$ and $5 \mathrm{~T}$

\begin{tabular}{|l|c|c|}
\hline Type & $2 \mathrm{~T}$ & $5 \mathrm{~T}$ \\
\hline Max. stored energy & $100 \mathrm{MJ}$ & $106 \mathrm{MJ}$ \\
\hline Constant output power & \multicolumn{2}{|c|}{$1 \mathrm{MW}$} \\
\hline Max. operating current & \multicolumn{2}{|c|}{$4 \mathrm{kA}$} \\
\hline Max. operating voltage & \multicolumn{2}{|c|}{$2 \mathrm{kV}$} \\
\hline Toroid aspect ratio & \multicolumn{2}{|c|}{0.6} \\
\hline Major radius & $3.68 \mathrm{~m}$ & $2.0 \mathrm{~m}$ \\
\hline Minor radius & $2.21 \mathrm{~m}$ & $1.2 \mathrm{~m}$ \\
\hline Unit coil outer radius & $2.28 \mathrm{~m}$ & $1.49 \mathrm{~m}$ \\
\hline Unit coil width & $0.41 \mathrm{~m}$ & $0.14 \mathrm{~m}$ \\
\hline Number of unit coils & \multicolumn{2}{|c|}{18} \\
\hline Magnet motive force & $13.8 \times 10^{6} \mathrm{~A}$ & $18 \times 10^{6} \mathrm{~A}$ \\
\hline Amount of conductor & $195 \times 10^{6} \mathrm{Am}$ & $152 \times 10^{6} \mathrm{Am}$ \\
\hline Max. hoop stress & $72 \mathrm{MPa}$ & $114 \mathrm{MPa}$ \\
\hline Centripetal force & $30 \mathrm{MN}$ & $68.6 \mathrm{MN}$ \\
\hline
\end{tabular}

\section{Cooling System of SMES Coil}

Liquid hydrogen, which has a high-flammability range, needs to be strictly adhered to keep special handling methods of storage and transport in order to avoid critical accidents. These safety measures for dealing with liquid hydrogen have to be applied not only outside air environment but also inside vacuum insulating. All high current circuits composed of the SMES coil system with 


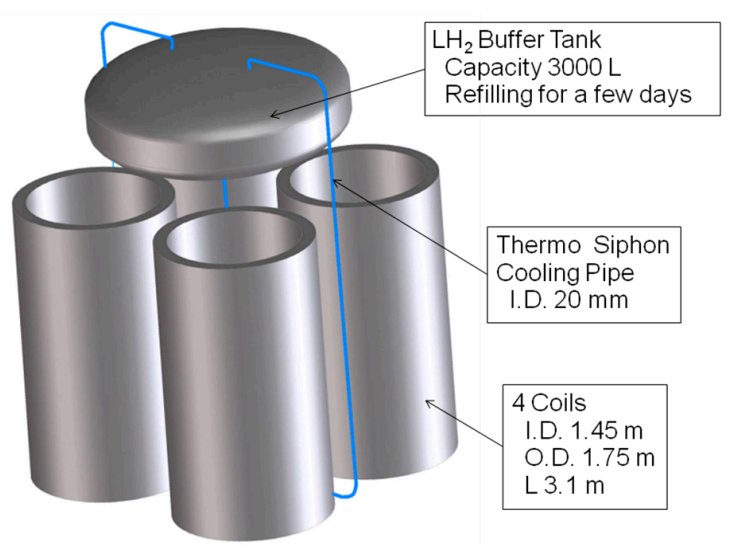

Fig. 9. $\mathrm{MgB}_{2}$ four-pole coil and thermo-siphon cooling system with buffer tank is composed.

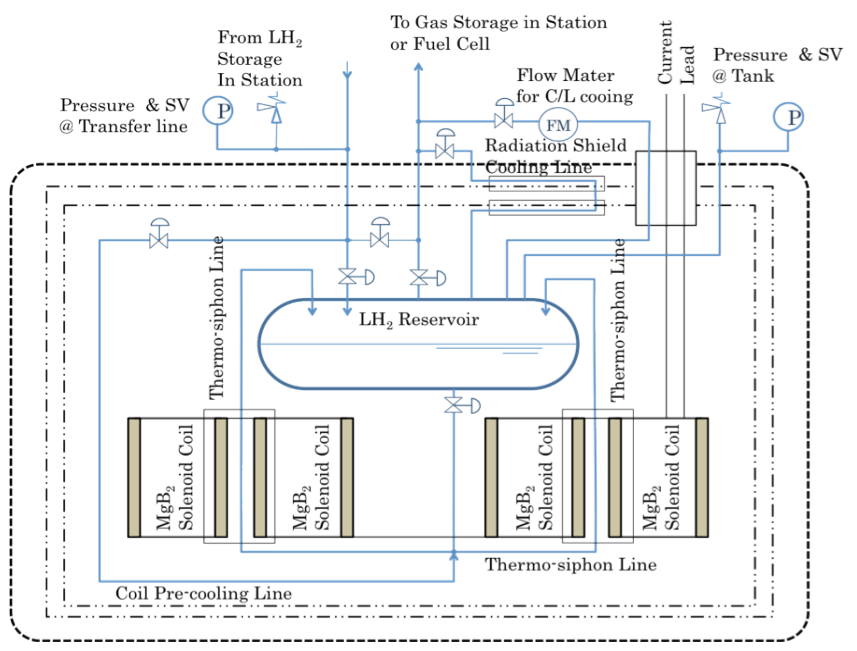

Fig. 10. Flow diagram in the SMES cryostat with thermo-siphon circulation.

the electrical lead lines have to be indirectly cooled across the electrical insulator. So, the coil cooling scheme by the thermo-siphon method is based on the design concept of the cryogen free magnets for particle detectors. Pure aluminum strips play a role of the thermal conductors for indirect cooling as shown in Fig. 6. The heat loads transferred from the coils are consumed as vaporization of liquid hydrogen. The liquid hydrogen is fed from the bottom of the reservoir tank and returned to its top gaseous region in the form of the thermo-siphon concept. The schematic SMES system and the flow diagram of the

Table III. - Parameters of SMES coil cooling system for the $2 \mathrm{~T}$ solenoid SMES

\begin{tabular}{|c|c|}
\hline Buffer tank: \\
\hline Tank capacity & $3 \mathrm{~m}^{3}$ \\
\hline Tank pressure & $150 \mathrm{kPa}$ \\
\hline Thermo-siphon circulation cooling circuit: \\
\hline Pipe channel diameter & $20 \mathrm{~mm}$ \\
\hline Pipe length & $20 \mathrm{~m}$ \\
\hline Pressure head & $1270 \mathrm{MPa}$ \\
\hline Flow rate per coil & $0.53 \mathrm{~g} / \mathrm{s}$ \\
\hline Coil cooling: & \\
\hline Cooling mode & $\begin{array}{c}\text { Conduction from thermo } \\
\text { siphon line }\end{array}$ \\
\hline Thermal conductor & Pure aluminum strip \\
\hline
\end{tabular}

thermo-siphon cooling system are shown in Figs. 7 and 8, respectively. As an example, the design parameters of the cryogenic system for the $2 \mathrm{~T}$ solenoid SMES are shown in Table III.

\section{Conclusion}

We propose the Advanced Superconducting Power Conditioning System (ASPCS) to compensate the fluctuations of renewable energy sources and to be their effective use. It becomes clear that the moderate fluctuations of wind or photovoltaic generations can be compensated by the trend prediction method using the Kalman filtering algorithm. The SMES that is one of the key components of the system compensates the shortterm fluctuations that cannot be compensated by the trend prediction. The design study of the SMES system is performed that the coil of $50 \mathrm{MJ}$ is composed of four 10 MJ basic coils of the solenoid type fabricated with $\mathrm{MgB}_{2}$ superconductors and also $100 \mathrm{MJ}$ coil of the toroid type in case of the maximum magnetic fields of $2 \mathrm{~T}$ and $5 \mathrm{~T}$. The $5 \mathrm{~T}$ coil is much more compact than the $2 \mathrm{~T}$ coil. For the safety, the coil is indirectly cooled at $20 \mathrm{~K}$ with liquid hydrogen by use of a thermo-siphon cooling system that had been developed for particle detectors.

In order to make the SMES system into economically practical use, the most important subject is to develop high performance $\mathrm{MgB}_{2}$ conductors. It is expected to improve the characteristics of critical current up to around $5 \mathrm{~T}$ for more compact SMES coil systems.

\section{Acknowledgement}

This work is supported by the Advanced Low Carbon Reduction Technology R\&D of the Japan Science and Technology Agency.

\section{References}

[1] "Feasibility study in response to hydrogen carriers in technology development of system to produce, transport and store hydrogen," NEDO Report P08003, 2009.

[2] M. Modica et al., "Construction and installation of cryogen free $\mathrm{MgB}_{2}$ magnets for open MRI systems," IEEE Trans. Appl. Supercond., vol. 18, no. 2, pp. 882-886, 2008.

[3] R. Musenich et al., "A $\mathrm{MgB}_{2}$ superferric racetrack magnet," Supercond. Sci. Tech., vol. 21, p. 105014, 2005.

[4] M. Tomsic et al., "Overview of $\mathrm{MgB}_{2}$ superconductor applications,” Int. J. Appl. Ceram. Technol., vol. 4, no. 3, pp. 250-259, 2007.

[5] H. Hirabayashi, Y. Makida, S. Nomura, and T. Shintomi, "Feasibility of hydrogen cooled superconducting magnet," IEEE Trans. Appl. Supercond., vol. 16, no. 2, pp. 14351438, 2006.

[6] T. Nakayama, T. Yagai, M. Makoto, and T. Hamajima, "Stability analysis of high temperature superconducting coil in liquid hydrogen," Physica $C$, vol. 463-465, pp. 1285-1288, 2007.

[7] Y. Makida, H. Hirabayashi, T. Shintomi, and S. Nomura, "Design of SMES system with liquid hydrogen for emergency purpose," IEEE Trans. Appl. Supercond., vol. 17, no. 2, pp. 2006-2009, 2007. 
[8] H. Hirabayashi, Y. Makida, S. Nomura, and T. Shintomi, "Liquid hydrogen cooled superconducting magnet and energy storage system," IEEE Trans. Appl. Supercond., vol. 18, no. 2, pp. 766-769, 2008.

[9] T. Nakayama, T. Yagai, M. Tsuda, and T. Hamajima, "Micro power grid system with SMES and superconducting cable modules cooled by liquid hydrogen," IEEE Trans. Appl. Supercond., vol. 19, no. 2, pp. 2062-2065, 2009.

[10] M. Sander and R. Gehring, "LIQHYSMES - A novel energy storage concept for variable renewable energy sources using hydrogen and SMES," IEEE Trans. Appl. Supercond., vol. 21, no. 2, pp. 1362-1366, 2011.

[11] T. Hamajima et al., "Application of SMES and fuel cell system combined with liquid hydrogen vehicle station to renewable energy control," to be published in IEEE Trans. Appl. Supercond., 2012.

[12] T. Shintomi et al., "Design study of SMES system cooled by thermo-siphon with liquid hydrogen for effective use of renewable energy", to be published in IEEE Trans. Appl. Supercond., 2012.

[13] M. Tomsic: private communication. 